\title{
Buğday Agro-Ekosistemlerinde Pestisitlerin ve Odun Sirkesinin Kültür Bitkisindeki Arthropodlara Etkileri Üzerine Bir Araştırma
}

\author{
İbrahim $\mathrm{KOÇ}^{1^{*}}$, Erdal Necip YARDIM ${ }^{2}$ \\ ${ }^{1}$ Bitlis Eren Üniversitesi, Çevre Mühendisliği Bölümü, Bitlis \\ ${ }^{2}$ Bitlis Eren Üniversitesi Rektörlüğ̈̈, Bitlis
}

\begin{abstract}
$\ddot{O} \mathbf{z}$
$\mathrm{Bu}$ çalışma, buğday agro-ekosisteminde bitki koruma amaçlı kullanılan pestisitlerin ve odun sirkesi'nin, kültür bitkisi üzerindeki arthropodlara etkisini belirlemek amacıyla yapılmıştır. Araştırma; Muş ili ekolojik şartlarında, 2014-2015 ve 2015-2016 üretim sezonlarında kışlık buğday tarlasında Tesadüf Blokları Deneme Desenine göre dört tekerrürlü olarak yürütülmüştür. Denemede yapılan ilaç uygulamaları; sırt pülverizatörü yardımı ile BERCE Alparslan Tarım İşletmesi’nin hastalık, zararlı ve yabancı otlarla mücadelede kullandığı pestisitler ve uygulama takvimi takip edilerek yapılmıştır. Çalışmada;

1) pestisit uygulamas1,

2) pestisit uygulamasına tekabül eden $\% 0.5-\% 1-\% 2$ - \%3 - \%4 ve \%5 mL odun sirkesi uygulamaları ve

3) herhangi bir ilaç (pestisit ve odun sirkesi) uygulamasının yapılmadığı kontrol uygulaması şeklinde yapılmıştır. Kontrole göre, yapılan uygulamaların (pestisit ve odun sirkesi) kültür bitkisi üzerindeki ortalama arthropod sayısını etkilediği ve yapılan Basit Uyum Analizleri sonucunda söz konusu uygulamalar ile dikkate alınan özellikler arasında genel olarak anlamlı ilişkilerin bulunduğu tespit edilmiştir. Ayrıca, 2014-2015'e göre 2015-2016'da kültür bitkisi üzerindeki arthropodların sayıca daha çok olduğu bulunmuştur. Sonuç olarak; odun sirkesinin, biyopestisit ile repellent (kovucu) etkilerinin tespiti için kontrollü şartlarda ve farklı dozlarda denenmesinin faydalı olabileceği düşünülmektedir.
\end{abstract}

Anahtar kelimeler: Agro-Ekosistem, Arthropodlar, Biyopestisitler, Buğday, Odun Sirkesi.

\section{A Research on the Effects of Wood Vinegar and Pesticides on Arthropods Living on Cultivated Plants in Wheat Agroecosystems}

\begin{abstract}
The aim of this study is to investigate the effect of pesticides which are used in wheat agroecosystem for plant protection and wood vinegar on arthropods living on cultivated plants. The investigation has been performed in same wintery wheat field according to Randomized Block Design with 4 replications in Muş province's ecological conditions in 2014-2015 and 2015-2016 growing seasons. Pesticides in the treatments were applied for disease, pests and weeds based on a calendar determined by BERCE Alparslan Agriculture Administration. The treatments in the study were;

1) pesticide application,

2) $0,5 \%, 1 \% \mathrm{~mL}, 2 \% \mathrm{~mL}, 3 \% \mathrm{~mL}, 4 \% \mathrm{~mL}, 5 \% \mathrm{~mL}$ wood vinegar corresponding to pesticide applications and

3) control application where no pesticide and wood vinegar used. Compared to the control, the applications (pesticides and wood vinegar) had an effect on the average number of arthropods on the cultivated plants and as a result of the Simple Correspondence Analysis Method, there were generally meaningful relations between the applications and the features considered. Moreover, the number of arthropods on the cultivated plants in 20152016 was found to be higher than those in 2014-2015. As a result; we believe it may be useful to try the wood
\end{abstract}

*Sorumlu yazar: ibrahimkoc47@gmail.com

Geliş Tarihi: 10/05/2018 Kabul Tarihi: 29/05/2018

Not: Bu çalışma “2017 Imeset Conference Bitlis” uluslararası konferansta sözlü olarak sunulmuştur. 
vinegar under controlled conditions and often with in different doses to determine its repellent and bio-pesticides effects.

Keywords: Agroecosystem, Arthropods, Bio-pesticides, Wheat, Wood Vinegar.

\section{Giriş}

Tarımsal mücadelede, pestisitlerin başarı sağlaması oldukça sevindirici olmakla birlikte bu maddelerin bilimsel denetimden yoksun, gelişi güzel ve aşırı dozda kullanılmaları sonucunda, yararlı canlılar ile çevrenin diğer unsurları olumsuz etkilenmektedir [1]. Tarımsal uygulamaların başlıca amacı; ekolojik dengeleri bozmadan birim alandan kaliteli ve bol ürün elde etmektir [2]. Bitki korumada, kullanılan sentetik pestisitlerin yoğun kullanımından ötürü oluşan problemler çeşitli alternatif yöntemlerin ve doğal pestisitlerin aranmasını zorunlu hale getirmiştir [3]. Doğal pestisitlerden olan biyopestisitler; hayvanlar, bitkiler, bakteriler ve çeşitli mineraller gibi birçok doğal maddeden elde edilebilmektedir [4]. Karbonizasyon işlemlerinin bir yan ürünü olarak üretilen odun sirkesi (OS), yapılan arkeolojik çalışmalarda bitki koruma amaçlı olarak Neanderthal zamanında kullanıldığı bulunmuştur [5]. OS'un \%80-90'1 su ve \%10-20'sinin ana kısmı asetik asit olmakla birlikte 200'den fazla organik birleşikten oluşmuştur [6]. OS; asetik asit ile birlikte organik asitler, fenolik, alkan, alkol ve ester ana bileşiklerinden meydana gelmiştir [7]. Bambudan elde edilen OS, termit ve böcek kontrolünde uygulanabilmektedir [8].

OS'un, su ve topraktaki hedef olmayan organizmalara karşı toksik ya da hafif toksik olduğu ifade edilmiştir [9].

Bu çalışma, buğdayda bitki koruma amaçlı kullanılan bazı pestisitlerin ve odun sirkesinin, kültür bitkisi üzerindeki arthropodlara etkilerini belirlemek amacıyla yapılmıştır.

\section{Materyal ve Metot}

\subsection{Materyal}

Deneme alanı; Muş il merkezine yaklaş1k 12 km mesafede bulunan BERCE Alparslan Tarım İşletmesine ait Krasunia odeska kışlık buğday tarlasında (14. Parsel, 1276 m yükseklik, 3847'33.0"N 4132'45.0"E koordinat) yürütülmüştür. Denemenin yapıldığı bölgedeki, son on yıl (uzun yıllar ortalaması), 1. yıl (2014-2015) ile 2. yılın (2015-2016) toplam yağış, ortalama sıcaklık ve ortalama nispi nem değerleri Tablo 1'de verilmiştir [10].

Tablo 1. Muş ili uzun yıllar ortalaması, 2014-15 ve 2015-16 yılları vejetasyon dönemine ait bazı iklim verileri

\begin{tabular}{ccccccccc}
\hline \multicolumn{3}{c}{ Yağıș $\mathbf{( m m )}$} & \multicolumn{3}{c}{ Ortalama Sıcaklık $\mathbf{( C}^{\mathbf{0}}$ ) } & \multicolumn{3}{c}{ Nispi Nem (\%) } \\
\hline $2014-15$ & $2015-16$ & UYO & $2014-15$ & $2015-16$ & UYO & $2014-15$ & $2015-16$ & UYO \\
\hline 740.4 & 790.1 & 740.5 & 11.55 & 11.48 & 10.62 & 55.02 & 54.00 & 60.79 \\
\hline
\end{tabular}

Bu çalışmada kullanılan OS; Broyler tavuk yetiştiriciliği atığından, gazlaştırma makinesi ile biyokömür ve OS ürünlerini geliştiren bir firmadan temin edilmiştir [11]. 2014-2015 üretim sezonu için; 26 Mayıs'ta, pestisit uygulanan parsellere: Herbisit Weed killer D (etken madde: 2,4-D Acid Dimethylamin, $100 \mathrm{~mL} / \mathrm{da}$, Koruma) ile fungisit Duett super (etken madde: $84 \mathrm{~g} / \mathrm{L}$ Epoxiconazole ve $250 \mathrm{~g} / \mathrm{L}$ Fenpropimorph, $100 \mathrm{~mL} / \mathrm{da}$, Basf), OS uygulanan parsellere; \%0.5, \%1, \%2, \%3, \%4 ve \%5 mL OS ve kontrol grubu parsellerine ise sadece su uygulanmıştır. 2015-2016 üretim sezonu için; pestisit uygulanan parsellere 24 Nisan'da fungusit İnput (etken madde: $160 \mathrm{~g} / \mathrm{L}$ Prothioconazole $+300 \mathrm{~g} / \mathrm{L}$ Spiroxamine, EC, $100 \mathrm{~mL} / \mathrm{da}$, Bayer), 30 Nisan'da herbisit Harmony platinum (etken madde: \%37.5 Thifensulfuron methyl+\%37.5 Tribenuron methyl, DF, 2 g/da, Bayer), 8 Mayıs'ta herbisit Attribut süper 
WG 20 (etken madde: \%6.75 Propoxy carbazone-sodium+\%4.5 Mesos ulfuron-methyl, WG, 20 g/da, Bayer) ile Biopower $(100 \mathrm{ml} / \mathrm{da}$, Bayer) karıştırılarak, 6 Haziran'da ise fungisit Duett super (etken madde: $84 \mathrm{~g} / \mathrm{l}$ Epoxiconazole ve $250 \mathrm{~g} / \mathrm{l}$ Fenpropimorph, $100 \mathrm{ml} / \mathrm{da}$, Basf), belirtilen tarihlerde OS uygulanan parsellere; $\% 0.5, \% 1, \% 2, \% 3, \% 4$ ve $\% 5 \mathrm{~mL} \mathrm{OS}$ ve kontrol grubu parsellerine ise sadece su uygulanmıştır.

\subsection{Metot}

Deneme alanı; 2014-2015 ve 2015-2016 üretim sezonlarında, Tesadüf Blokları Deneme Desenine göre ve dört tekerrürlü olarak yürütülmüştür. Her bir parsel $25 \mathrm{~m}^{2}(5 \mathrm{x} 5 \mathrm{~m})$ büyüklüğünde olup bloklar ve parseller arasında en az $2 \mathrm{~m}$ mesafe bırakılmıştır [12]. İlaç uygulamaları; sırt pülverizatörü yardımı ile BERCE Alparslan Tarım İşletmesinin buğdayda kullandığı pestisitler ve uygulama takvimi takip edilerek yapılmıştır. Çalışmada şu muameleler kullanılmıştır:

1) pestisit uygulaması; buğdayda görülen hastalık ile yabancı otlara ve gerektiğinde zararlılara karşı kullanılan ilaçlar uygulanmıştır.

2) pestisit uygulamasına tekabül eden $\% 0.5-\% 1-\% 2-\% 3-\% 4-\% 5 \mathrm{~mL}$ OS ve

3) herhangi bir ilaç (pestisit ve OS) uygulamasının yapılmadığı kontrol uygulaması şeklinde yapılmıştır.

Genel anlamda, yapılan ilaç uygulamalarının kültür bitkisi üzerindeki arthropodlara (Carabidae, Coccinellidae, Formicidae, Gryllidae, Aphididae, Apidae, Araneae gibi) olan etkisinin tespiti için; her ilaçlamadan sonra ve diğer zamanlarda (haftalık olarak) her parselden rastgele seçilen 10 bitkideki arthropod bulunma durumuna bakılarak arthropod bulaşıklı bitki olarak (Şekil 1) kaydedilmiştir.
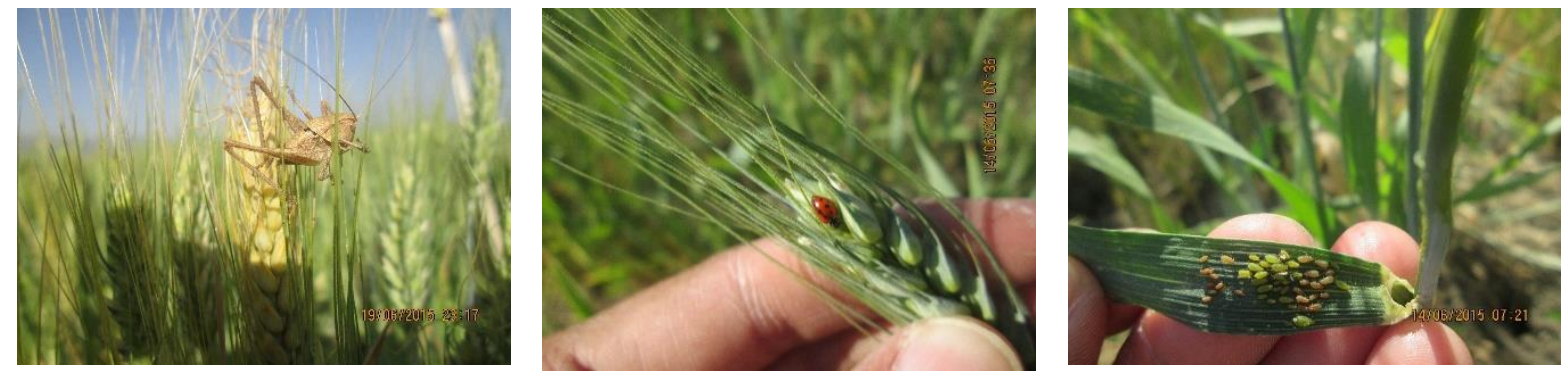

Şekil 1. Arthropod bulaşıklı bitkilere örnek

2014-2015 üretim sezonunda: 29 Mayıs, 7 Haziran, 19 Haziran, 26 Haziran ve 3 Temmuz'da olmak üzere 5 defa; 2015-2016 üretim sezonunda: 05 Mayıs, 09 Mayıs, 15 Mayıs, 22 Mayıs, 07 Haziran, 14 Haziran, 22 Haziran ve 29 Haziran'da olmak üzere toplamda 8 defa arthropod bulaşıklı bitki sayımı yapılmıştır. Bu çalışmadan elde edilen verilerin istatistik analizlerinde; Basit Uyum Analizi Tekniğinden (Simple Correspondence) yararlanılmış olup, analizler Minitab (Ver. 17) istatistik paket programında yapılmıştır [13].

\section{Bulgular ve Tartışma}

26 Haziran 2015 örneklemi pestisit uygulaması ile, 7 ve 19 Haziran 2015 örneklemleri \%1 mL OS uygulaması ile, kontrol - \%3 - \%4 ve $\% 2 \mathrm{~mL}$ OS uygulamaları ise kendi aralarında ilişkili olduğu görülmüş̧ür (Şekil 2 ve Tablo 2). 

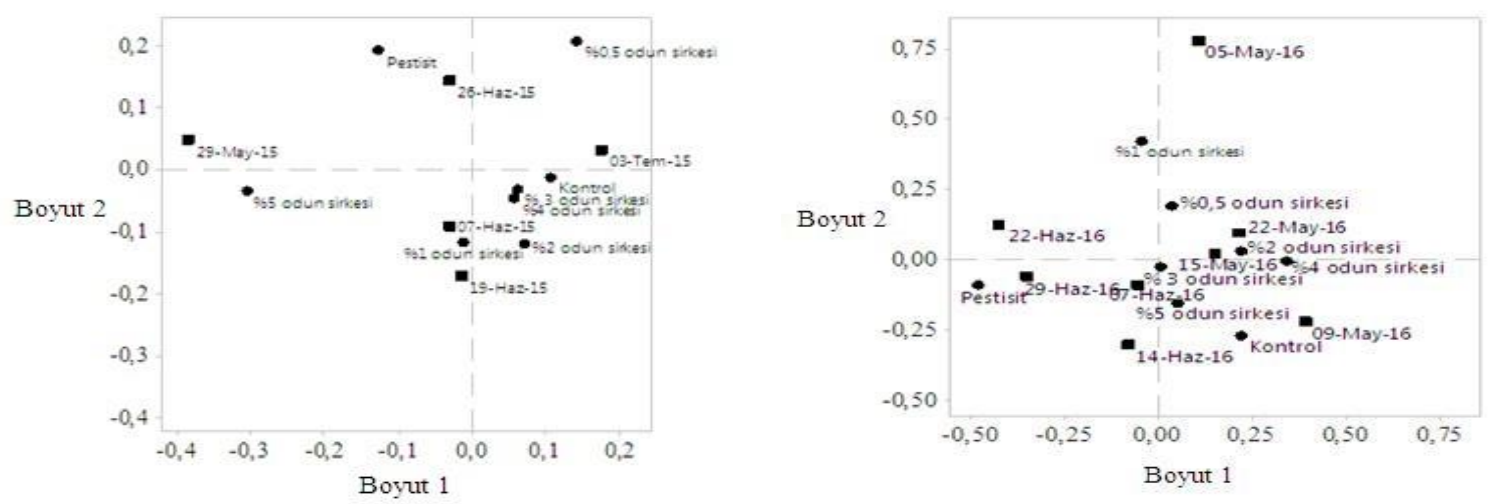

Şekil 2. Arthropod bulaşıklı bitki sayısı bakımından, 2014-2015 yılı (sol) ve 2015-2016 (sağ) uygulama ve örneklem tarihleri arasındaki ilişkiler için basit uyum analizi grafiği

Kültür bitkisinde bulunan arthropodlar; 2014-2015 üretim sezonunda en az \%0.5 mL OS'de (16.4) olup en çok kontrolde (21), 2015-2016 üretim sezonunda en az \%0.5 mL OS'de (10.37) olup en çok pestisitte (30.6), ortalama olarak ise en az \%0.5 mL OS'de (13.23) olup en çok pestisitte (24) tespit edilmiştir (Şekil 3).

Tablo 2. Arthropod bulaşıklı bitki sayısı bakımından 2015 yılı uygulama ve örneklem tarihleri arasındaki ilişkiler için basit uyum analizi tablosu

\begin{tabular}{ccccl}
\hline Axis & Inertia & Proportion & Cumulative & Histogram \\
\hline 1 & 0.0189 & 0.5528 & 0.5528 & $* * * * * * * * * * * * * * * * * * * * * * * * * *$ \\
2 & 0.0131 & 0.3842 & $\mathbf{0 . 9 3 7 1}$ & $* * * * * * * * * * * * * * * * * *$ \\
3 & 0.0016 & 0.0469 & 0.9840 & $* *$ \\
4 & 0.0005 & 0.0160 & 1.000 & \\
\hline Total & 0.0341 & & & \\
\hline
\end{tabular}

29 Haziran 2016 örneklemi pestisit uygulaması ile, 15 ve 22 Mayıs 2018 örneklemleri \%2 mL OS ile, 9 Mayıs örneklemi kontrol ile ilişkili olup 5 Mayıs ve 22 Haziran 2016 örneklemlerinin hiçbir uygulama ile ilişkisinin olmadığ tespit edilmiştir (Şekil 2 ve Tablo 3).

Tablo 3. Arthropod bulaşıklı bitki sayısı bakımından 2016 yılı uygulama ve örneklem tarihleri arasındaki ilişkiler için basit uyum analizi tablosu

\begin{tabular}{ccccl}
\hline Axis & Inertia & Proportion & Cumulative & \multicolumn{1}{c}{ Histogram } \\
\hline 1 & 0.0704 & 0.5310 & 0.5310 & $* * * * * * * * * * * * * * * * * * * * * * * * * * *$ \\
2 & 0.0367 & 0.2766 & $\mathbf{0 . 8 0 7 6}$ & $* * * * * * * * * * * * * *$ \\
3 & 0.0155 & 0.1172 & 0.9248 & $* * * * * *$ \\
4 & 0.0077 & 0.0582 & 0.9830 & $* * *$ \\
5 & 0.0012 & 0.0090 & 0.9920 & \\
6 & 0.0010 & 0.0074 & 0.9994 & \\
7 & 0.0001 & 0.0006 & 1.0000 & \\
\hline Total & 0.1327 & & & \\
\hline
\end{tabular}

2014-2015 üretim sezonuna göre (149.6), 2015-2016 üretim sezonunda (147.57) arthropod bulaşıklı bitki sayısı ortalamasının nispi derecede daha az olduğu bulunmuştur. 


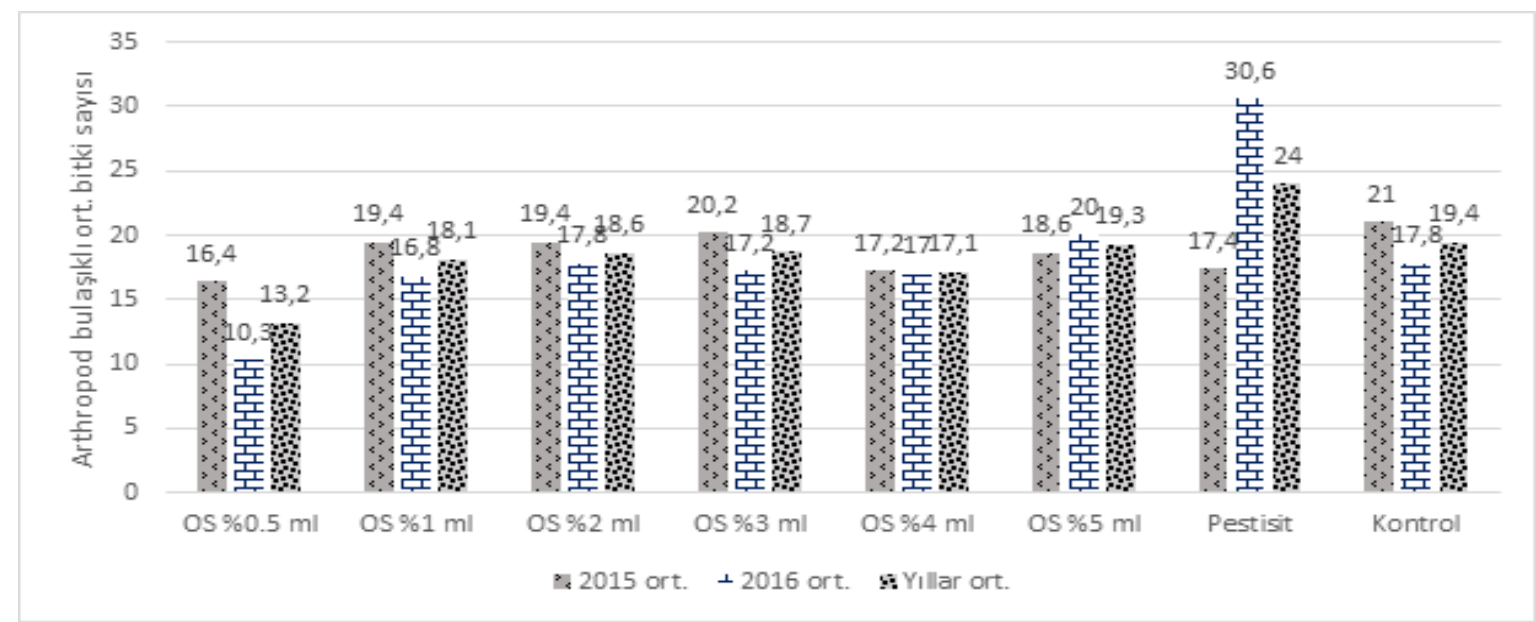

Şekil 3. 2014-2015 ve 2015-2016 üretim sezonları için, yapılan uygulamaya göre arthropod bulaşıklı ortalama bitki sayıs1

26 Haziran 2015 örnekleminin pestisit ile, 7 ve 19 Haziran 2015 örneklemlerinin \%1 mL OS ile çok sayıda arthropod bulaşıklı bitki bulunmakla ilişkili olduğu farz edilmektedir. 2014-2015 üretim sezonundaki kontrol - \%3 - 4 ve $2 \mathrm{~mL}$ OS uygulamalarının ise yapılan uygulamalardan benzer şekilde etkilenmekle ilişkili olduğu düşünülmektedir (Şekil 2). 29 Haziran 2016 örnekleminin pestisit uygulaması ile en çok sayıda arthropod bulaşıklı bitki bulunmakla ilişkili olduğu düşünülmektedir. 15 ve 22 Mayıs 2016 örneklemlerinin \%2 mL OS uygulaması ile en çok sayıda arthropod bulaşıklı bitki sayısı artmakla ilişkili olduğu öngörülmektedir. 9 Mayıs 2016 örnekleminin kontrol uygulaması ile en çok sayıda arthropod bulaşıklı bitki bulunmakla ilişkili olduğu farz edilmektedir. 5 Mayıs ve 22 Haziran 2016 örneklemlerinin homojen olmayan dağılımlardan dolayı hiçbir uygulama ile ilişkisinin olmadığı öngörülmektedir (Şekil 2). 2014-2015'e (149.6) göre, 2015-2016'da (147.57) arthropod bulaşıklı bitki sayısı ortalamasının daha az olması, 2015-2016'da daha çok ilaçlama yapılmasından ve kullanılan ilaçların predatör arthropodları öldürmesinden ya da kovucu etki göstermesinden dolayı özellikle afit popülasyonlarının artmasından ötürü olabileceği düşünülmektedir. $\mathrm{Bu}$ çalışmadan elde edilen sonuçların, benzer çalışmalar $[6 ; 8 ; 13 ; 14 ; 15 ; 16 ; 17]$ ile örtüştüğü tespit edilmiştir. Elde edilen bulguların dalgalanmalar göstermesi durumu, stabil olmayan iklim koşulları ve ilaç uygulamalarının yabancı ot ile bitki gelişimi üzerindeki etkilerinin dolaylı olarak arthropodları etkilemesinden kaynaklanabileceği öngörülmektedir.

\section{Sonuç ve Öneriler}

Gerek pestisit ve gerekse odun sirkesi uygulamalarının, kültür bitkisi üzerinde bulunan arthropodlar üzerinde direkt veya dolaylı bir şekilde etkili olduğu tespit edilmiştir. Daha çok kâr ve verim elde etmeye odaklanmanın yanında biyolojik çeşitliliğe müdahale etmeden, toprağı destekleyici, çevreye ve özellikle doğal düşmanlara zarar vermeyen ürünlere yönelmemiz, yerkürenin korunması ve sürekliliğin sağlanması için hayati önem arz etmektedir. Bu bağlamda örnek teşkil eden odun sirkesi'nin insektisit veya kovucu özelliğinin tespiti için farklı doz, ortam (laboratuvar, sera ile tarla) ve sıklıklarda arthropodlar üzerinde denenmesinin faydalı olacağı düşünülmektedir. 


\section{Kaynaklar}

1. Dığrak M., Kaçar N., Sönmez A. 1999. Pomarsol, Mitikol, Rubigan Ve Platoon'un Toprak Mikroflorası Üzerine Etkileri, Turkish Jounal of Agriculture and Forestry, 23 (5): 1071-1077.

2. Topal S. 2011. Allelokimyasalların Herbisit Etkileri, Dumlupınar Üniversitesi Fen Bilimleri Enstitüsü Dergisi, 25: 23-26.

3. Erdoğan P., Toros S. 2005. Melia azaderach L. (Meliaceae) Ekstraktlarının Patates Böceği [Leptinotarsa decemlineata Say (Col.:Chrysomelidae)] Larvalarının Gelişimi Üzerine Etkisi, Bitki Koruma Bülteni, 45 (1-4): 99-118.

4. Yarsan E., Çevik A. 2007. Vektör Mücadelesinde Biyopestisitler, Türk Hijyen ve Deneysel Biyoloji Dergisi, 64 (1): 61-70.

5. Tiilikkala K., Fagernäs L., Tiilikkala J. 2010. History and Use of Wood Pyrolysis Liquids as Biocide and Plant Protection Product, The Open Agriculture Journal, 4 (1): 111-118.

6. Kim D.H., Seo H.E., Lee S., Lee K. 2008. Effects of Wood Vinegar Mixted with Insecticides on the Mortalities of Nilaparvata lugens and Laodelphax striatellus (Homoptera: Delphacidae), Animal Cells and Systems, 12 (1): 47-52.

7. Jothityangkoon D., Koolachart1 R., Wanapat1 S., Wongkaew S., Jogloy S. 2008. Using Wood Vinegar in Enhancing Peanut Yield and in Controlling the Contamination of Aflatoxin Producing Fungus, International Crop Science, 4: 253-253.

8. Inoue S., Hata T., Imamura Y., Meier D. 2000. Components and Anti-Fungal Efficiency of Wood Vinegar Liquor Prepared Under Different Carbonization Conditions, Wood Research: Bulletin of the Wood Research Institute Kyoto University, 87: 34-36.

9. Hagner M. 2013. Potential of the Slow Pyrolysis Products Birch Tar Oil, Wood Vinegar and Biochar in Sustainable Plant Protection - Pesticidal Effects, Soil Improvement and Environmental Risks. Department of Environmental Sciences Faculty of Biological and Environmental Sciences University of Helsinki, Thesis, Finland.

10. Anonim, 2016a. Muş Meteoroloji İl Müdürlüğü Kayıtları. https://www.mgm.gov.tr/ kurumsal/istasyonlarimiz.aspx?ssirala=al\&m=mus. (Erişim tarihi: 05.11.2016).

11. Namlı A., Akça M.O., Turgay E.B., Soba M.R. 2014. Odun Sirkesinin Tarımsal Kullanım Potansiyelinin Araştırılmas1, Toprak Su Dergisi, 3 (1): 44-52.

12. Winer B.J., Brown D.R., Michels K.M. 1971. Statistical Principles in Experimental Design, Vol. 2. McGraw-Hill, New York.

13. Chalermsan Y., Peerapan S. 2009. Wood Vinegar: By-Product From Rural Charcoal Kiln And Its Role In Plant Protection, Asian Journal of Food and Agro-Industry, 189-195.

14. Rimaz V., Valizadegan O. 2013. Toxicity of Agricultural Adjuvant Cytogate Oil and the Insecticide Pymetrozine to the Cabbage Aphid, Brevicoryne brassicae L. (Hemiptera: Aphididae) and its Parasitoid, Diaeretiella rapae M. (Hymenoptera: Aphidiidae), Egyptian Journal of Biological Pest Control, 23 (2): 221-225.

15. Gültekin Ü., Jepton P.C. 1991. The Toxicity of Aphicide Residues to Beneficial Invertebrates in Cereal Crops, Annals of Applied Biology, 118 ( 3): 493-502. 
16. Özmen M. 2009. Yonca Hortumluböceği [Hypera postica Gyllenhal (Coleoptera: Curculionidae)]'ne Karşı Değişik Dönemlerde Yapılan İlaçlamaların Yonca (Medicago Sativa L.) 'da Zararlı, Doğal Düşman ve Verim Üzerine Etkileri. Yüzüncü Y1l Üniversitesi, Fen Bilimleri Enstitüsü, Yüksek lisan tezi, Van.

17. Evans S.C., Shaw E.M., Rypstra A.L. 2010. Exposure to a Glyphosate-Based Herbicide Affects Agrobiont Predatory Arthropod Behaviour and Long-Term Survival, Ecotoxicology, 19 (7): 12491257. 